\title{
Estágio: contribuições para a formação do professor de história*
}

Sandra Agostini ${ }^{1}$

Elison Antonio Paim ${ }^{2}$

RESUMO

Este artigo tem como base a pesquisa intitulada: "Estágio: contribuições para a formação do professor de História", e objetivou entender como os professores de História avaliam o estágio enquanto elemento constitutivo de sua formação inicial. Utilizamos a metodologia da História Oral. Os depoentes avaliam a Graduação, a importância do estágio, as lacunas existentes no estágio e no próprio curso; fizeram críticas e sugestões que contribuem significativamente para 0 aperfeiçoamento das atividades de estágio.

Palavras-Chave: formação de professores, estágio, experiência, relação teoriae prática

0 presente artigo advém das reflexões da pesquisa, intitulada: "Estágio: contribuições para a formação do professor de História", e objetivou entender como os professores de História licenciados pela UNOCHAPECó avaliam o estágio enquanto elemento constitutivo de sua formação inicial.

Para a elaboração da pesquisa, buscamos os dados numa perspectiva qualitativa, através das fontes orais, pois, a história oral permitiu aos depoentes falar de suas vivências, suas experiências relatando como perceberam a sua formação inicial. Nos fundamentamos, especialmente, em PORTELLI (1997), o qual apresenta a História Oral como uma metodologia que nos permite vivenciar o passado através da memória das pessoas entrevistadas. Ressalta também a importância de saber ouvir, pois "nossa arte de ouvir enriquece

\footnotetext{
"Pesquisa financiada pelo Fundo de Apoio a Pesquisa - FAPE, da UNOCHAPECÓ.

1 Graduada em História pela UNOCHAPECÓ. sandraagostini@bol.com.br

2 - Doutorando em Educação da UNICAMP, professor de Prática de Ensino de História na UNOCHAPECÓ. elisonpaim@hotmail.com
} 
nossa experiência" (p.17). BENJAMIN: (1993), que procura nos mostrar que um meio de se adquirir experiência é ouvir as experiências relatadas pelos outros no processo de rememoração. Para entender os problemas da dicotomia entre teoria e prática, buscamos como suporte REG0: (1992), a qual afirma que há uma grande contradição entre teoria e prática nos cursos de licenciatura; Quanto às metodologias e a formação do professor, buscamos fundamentos em FONSECA: (1986; 1997), a qual aborda as necessidades de mudar as metodologias de ensino, investindo mais na pesquisa e na formação permanente do professor; A questão da importância do estágio é abordada por PONTUSCHKA: (1991), a qual demonstra a importância do estágio para a formação do professor, e por outro lado, considera que este é um momento para verificar o acerto de sua escolha profissional e, também, foram importantes às contribuições de KENSKI (1991). Foi igualmente importante a contribuição de THOMPSON (1981) ao nos fornecer o conceito de experiência. No decorrer da pesquisa, buscamos também outras bibliografias complementares para nos apoiar no desenvolvimento na análise e escrita desse artigo.

0 presente artigo está estruturado procurando fazer a apresentação dos sujeitos da pesquisa; a importância do estágio na formação dos futuros professores e as sugestões para 0 seu aperfeiçoamento; destacamos ainda, as experiências vividas pelos professores depoentes no período do estágio.

0 desenrolar do processo teve início a partir das entrevistas realizadas com professores de História egressos da UNOCHAPECÓ, formados nos anos 2000 e 2002, residentes nos Estados de Santa Catarina e Rio Grande de Sul. Foram entrevistados os professores: Anderson, Elenita, Gilberto, Lauci, Lucimar, Maria Regina, Terezinha e Valentina.

No decorrer das entrevistas podemos perceber que o curso de História da UNOCHAPECÓ necessita passar por várias modificações quanto ao método de ensino e também rever as divergências internas que acabam prejudicando os acadêmicos como nos contou o professor Lauci:

Primeiro que o curso de História da UNOCHAPECó ele tem muitas contradições, ele acaba sendo um curso onde você tem diferentes linhas de pensamento, e alguns professores acabam não respeitando a linha de pensamento que você seguiu e acabam te marcando isso. Isso fica bastante claro lá (...) Isso fez com 
que o curso hoje seja bastante deficitário pra você trabalhar em sala de aula e muito do que você aprende lá, não acaba utilizando (...) não serve para escola (...) Eu acho que o curso de História tem que passar por uma modificação (...) 0 curso de História, eu acredito, primeiro, que ele está pecando em não ter uma bibliografia básica (...) você pega professores lá, que estão (...) utilizando há oito anos o mesmo texto. 0 mesmo texto que eu analisei eles estão analisando (...) Que dize que não houve crescimento nenhum (...) Eu acredito que hoje, quando tu entra, tem uma visão do curso de História e quando tu sai tem uma visão cinqüenta por cento negativa de quando você entrou. Quando tu vai pra sala de aula é pior ainda (...) a realidade é diferente, é contraditória (...) Eu acredito hoje que o curso (...) não todo, mas em alguns momentos ele colabora para que 0 sistema se mantenha como está.

A sua narrativa nos remeteu SCHMIDT (1996, p. 118), quando nos diz que: "Ensinar História passa a ser, então dar condições para que o aluno possa participar do processo do fazer, do construir a História".

E, também, ocorre um certo esquecimento da Universidade, do Curso de História para com os ex-acadêmicos, como nos apontou a professora Maria Regina:

Eu acho que deveria ter nas Escolas e que eu senti falta não sei se foi falta de comunicação da Universidade, do Curso perante os professores que já se formaram (...) então, a Universidade, assim, (...) até porque não se manda folder? Eu acho que isso também é estágio envolver mais os professores de História né!

A formação de professores vai além do curso de graduação e precisa estar em permanente formação, pois, "para o professor saber fazer ele precisa ser uma pessoa, e como tal em constante formação, assim como, o fazer que é 0 aspecto social da sua prática docente, também exige uma permanente formação" (CARVALHO, 1999, p.90).

Os professores como seres humanos se constroem em sociedade, ou seja, em ambientes sociais tais como em família, na Escola, na Universidade e, posteriormente, na Escola como profissionais; esta construção é permanente a acontece nas mais diversas relações sociais. Especialmente, no aspecto profissional onde fazer-se é inteiramente social e acima de tudo humanizador. 
Outro aspecto considerado como contraditório no curso de História pelos depoentes é o Estágio de Regência, poder ser realizado como curso de extensão, como nos colocou o professor Lauci:

Eu acredito também que um doserros do estágio hojeévocêpoder fazer teu estágio, por exemplo, como curso de formaçã̃o. Eu acredito que o cara, sujeito que faz curso de formação ele não ta indo para a sala de aula (...) Eu acho que tem que ter o estágio em sala de aula. Que em sala de aulaé aonde ele vai é conhecer a realidade.

Analisando as entrevistas, podemos dizer que os professores entrevistados consideram o estágio como de extrema importância para sua formação, com exceção da professora Maria Regina que em sua fala fica explícito que:

Eu acho importante o estágio. A partir do momento que a pessoa que tá fazendo faculdade e ela não é professora (...) assim o estágio me ajudou a perceber algumas modificações que poderia ter na sala de aula como professora, mas eu acho que foi o curso de História que me fez perceber a mudança de postura que eu deveria ter na sala. Não o estágio! Entendeu? 0 estágio me ajudou a perceber outras questões do meu trabalho, da minha pesquisa, mas o trabalho do estágio ajuda na sala.

Evidencia-se assim que o estágio tem maior importância e é válido para aquele acadêmico que nunca atuou em sala de aula, que não tem experiência como nos afirmou a professora Terezinha:

0 estágio para mim, (...) foi uma coisa, assim, que fazia parte da minha história, porque eu já era professora na época em que eu fiz o estágio. Então, para mim não foi muito diferente, mas eu acho muito importante sim o estágio, principalmente para quem ainda não teve a experiência, o estágio te leva a observar como estar se organizando, como ter segurança, é como os alunos se comportam diante de uma sala de aula, quais seriam as formas de você se organizar né para o trabalho, eu acho que o estágio é necessário né, é uma coisa muito importante pra você ter noção de como que é ser professor mesmo. 
Embora o estágio seja considerado de extrema importância para os professores, principalmente para aquele professor (estagiário) que nunca entrou em uma sala de aula. Porém ele ajuda os professores atuantes a perceberem os erros cometidos e a fazer algumas modificações na sua maneira de lecionar. Assim: " 0 estágio representa para 0 aluno uma oportunidade de verificar 0 acerto de sua escolha profissional, já que é o momento em que a situação ensino-aprendizagem se realiza em toda a sua plenitude" (PONTUSCHKA, 1991, p. 179).

Portanto, é no estágio que se adquire algumas experiências necessárias para a prática a ser utilizada em sala de aula. Demonstrando que é possível fazer um ensino bem diversificado, saindo daqueles conteúdos tradicionais, procurando através de inovações oferecer aos alunos uma aula agradável trocando conhecimentos com eles, fazendo com que os alunos sintam-se sujeitos históricos como nos mostra REGO (1992, p. 40):

O estágio deve ser uma experiência criativa e enriquecedora para o futuro professor, e não, um espaço onde vai reproduzir na prática, ensinar não é, apenas, transmitir conhecimentos; é fazer do aluno o agente da construção de seu próprio saber e de sua prática social. Cabe ao professor prover as experiências adequadas e necessárias e orientar os alunos na vivência dessas experiências.

De acordo com os professores entrevistados, as metodologias utilizadas durante o período do estágio, devem ser bem diversificadas e criativas, de forma a fazer com que os alunos participem e possam contribuir com o trabalho do estagiário, como nos revelou a professora Terezinha:

Eu acho que a metodologia ela deve ser criativa (...) a metodologia deve ser participativa, ou seja, onde que inclua o aluno de onde que ele se intere (...) 0 estagiário precisa estar se organizando com várias coisas, não só com o estilo, por exemplo, se ele tem um filme que o filme seja muito curtinho, que a partir do filme ele consiga então estar mediando um trabalhinho com os alunos, mas que eles depois apresentem, participem. Se for através de trabalho em grupo que também não seja muito extenso, que seja assim uma coisa que atraia a atenção e que ele também consiga entender, que seja uma linguagem muito fácil para ele no momento (...) para que ele consiga contribuir para com o estagiário.

Como vimos, os professores estagiários precisam estar bem preparados e 
utilizando todas as metodologias disponíveis no momento para que a sua primeira experiência seja realizada com sucesso e para que este estagiário se identifique como professor e continue buscando o seu lugar em uma sala de aula. Como afirmou KENSKI (1991, p. 49):

0 estágio (...) e, a partir daí, a construção de nosso próprio modelo de ação docente em um processo complexo de interligações entre experiência e conhecimento teórico-prático, é um dos caminhos para se alcançar a nossa própria identidade e autonomia de ação.

Conforme os depoimentos destes professores o estágio necessita ser aperfeiçoado em vários sentidos, como nos colocou o professor Anderson:

0 estágio pode melhorar, o professor orientador assistiu poucas aulas minhas é uma reclamação (...) deveria ter sido até maior a participação né, e também uma avaliação com o professor depois do estágio não só uma avaliação por escrito no relatório, mas mesmo uma conversa informal né. Tendo a contribuição desse orientador.

Já na opinião do professor Lauci:

Eu acho que tem que mudar o estágio de observação, você acaba fazendo 10, 12 horas ali, você observa um professor (...) eu acho que ele tinha que ser menor, com cada professor, mas, você trabalhar com vários professores aí seria mais interessante pra você até conhecer a realidade da escola né (...) da escola pública municipal da rede estadual e até mesmo da rede particular. Quais são as diferenças? (...) o estágio eu dividiria em 3 partes (...) a questão do professor, por exemplo, que está em sala de aula, e o estágio ele serve para que você consiga fazer algumas mudanças né (...) e o segundo é aquele professor que nunca entrou em sala de aula, então aquele professor eu acho até mais válido porque você acaba entrando aí em contato com o aluno, com a escola e em si, né, e o terceiro é (...) essa dicotomia que trás então entre o que você planeja e o que você vai enfrentar na realidade porque hoje a realidade da escola pública e isso é uma das questões assim, fundamentais que eu acho que a Universidade tinha que trabalhar mais. 
Na visão da professora Valentina Marchiori, o aperfeiçoamento do estágio: "vai depender muito de cada profissional. Porque pra você ser um bom profissional você tem que estar realmente pesquisando. Eu acho a pesquisa fundamental, sem pesquisa não tem nada gente!" Sua fala expressa que sendo a pesquisa vinculada ao estágio em sala de aula e que esta tem por finalidade produzir conhecimentos, isto nos leva a refletir como os professores vem sendo formados numa perspectiva em que:

Os processos de profissionalização tem sido utilizados para introduzir sistemas de racionalização no ensino, de tal modo que o fruto foi a homogeneização das práticas dos docentes, a conseqüente burocratização e perda da autonomia dos professores no banimento da participação social na educação cada vez justificado como âmbito de decisão dos profissionais ou da administração" (POPKEWITZ, 1999, apud CONTRERAS, 2002, p.61) .

Qual é o perfil do professor que se quer formar? Atualmente as preocupações com a formação de professores vêm no sentido da emancipação do professor como um sujeito que tome as decisões, que produza conhecimentos, ou, no mínimo, entenda como foram construídos os conhecimentos que ele deve ensinar. Por isso, a necessidade de conciliar o ensino à pesquisa, pois nessa perspectiva:

A construção da autonomia além de ocorrer no debate público com setores dirigentes, também deve ter a dimensão da sala de aula, nas relações que lá se constroem, é preciso que as relações entre professores e alunos se desenvolvam no diálogo onde se explicite as posições, se construam relações mais democráticas, participativas... Pois como ato de ensinar e aprender são uma via de mão dupla, é preciso construir formas para que a autonomia do professor seja exercida; porém, tal possibilidade de realização só pode se dar se os estudantes entenderem seu propósito e seu plano, e seu professor entender as circunstâncias e expectativas daqueles (CONTRERAS, 2002, p. 198).

Ao vincular o estágio a pesquisa visando à produção de conhecimento onde o professor não seja apenas um transmissor de conteúdos já estabelecidos 
pelos manuais didáticos - quebra-se, assim, a hierarquia existente entre os que pensam e os que executam, ou seja, pesquisam e ensinam.

Nesse sentido, para o aperfeiçoamento do estágio na opinião do professor Gilberto, seriam necessárias mais horas aulas, mas sempre com um professor auxiliando como ele nos falou:

Eu acredito que hoje conforme funciona 0 estágio ele é uma coisa muito momentânea. 0 estágio deveria ser pensado a meu ponto é como uma coisa mais longa, um acompanhamento mais longo, um professor sempre guiando (...) acho que o estágio deveria ser uma coisa mais contínua.

Pelos depoimentos dos professores entrevistados, com exceção de uma professora, o estágio contribuiu efetivamente no seu crescimento profissional. A princípio por ser o primeiro contato que o professor terá com a profissão que irá desenvolver. E mesmo para aquele professor que já está atuando o estágio faz com que ele repense 0 ensino, revendo suas metodologias e a sua maneira de ensinar. Mas o estágio também é visto como um momento único no qual o professor tem a liberdade de estar tentando inovar o ensino através de várias metodologias que terão como objetivo fazer da aula de História uma aula agradável que 0 aluno goste.

Outro aspecto destacado pelos professores entrevistados foi com relação a teoria e a prática. Que segundo eles auxiliaram seu desempenho no estágio. Pois sem as aulas teóricas não saberiam 0 que por em prática. Mas, que também existem os problemas da dicotomia teoria e prática como nos falou 0 professor Gilberto: "A teoria e a prática eu acho que vai ter sempre esse problema acho que essa dicotomia existe e é constante (...)".0 seu depoimento remetenos, mais uma vez a PONTUSCHKA (1991, p. 133), quando nos diz:

Nesse sentido, os cursos de formação de professores precisam recuperar a unidade entre a teoria e a prática educativa, de modo que a teoria seja o pensar e o repensar crítico sobre a prática à procura de sua compreensão global, visando a garantir uma prática transformadora. 
Apesar de existirem os problemas da dicotomia teria e prática, as aulas teóricas auxiliaram os professores entrevistados nos período do estágio, principalmente, para aqueles professores que já estavam atuando em sala de aula. Mas, essa dicotomia existe e é constante, devido a forma como nos é colocada na universidade, ou ainda, "uma teoria colocada no começo dos cursos e uma prática colocada no final deles sob a forma de estágio supervisionado constituem a maior evidencia da dicotomia existente entre a teoria e prática" (AZEVEDO, 1991, p.17).

Atualmente, faz-se necessário repensar a formação de professores, bem como, rever as metodologias de ensino. Como nos revelou a professora Lucimar:

Sabe, que você, assim, vê, que hoje está tão difícil de você competir com certas, por exemplo, a televisão, de repente tá ali o professor com um pedaço de giz e o quadro negro e daí tem, uma televisão que te transmite uma série de imagens. Até isso eu acho que hoje é difícil o professor estar competindo com a tecnologia que a Escola, de repente, não tem acesso, nós não temos Internet, por exemplo, né, a nossa biblioteca é muito boa, tem olha livros clássicos que eu vou te contar, mas, às vezes, eu vejo assim que com a televisão principalmente com os alunos ah Ensino Fundamental, por exemplo, é complicado.

$\mathrm{Na}$ fala da professora fica explícito que, atualmente, há uma grande competição entre o professor e as tecnologias. Por isso faz-se necessário que ocorra mudanças na formação do professor e nos métodos d'e ensino. Segundo FONSECA (1996, p. 108):

Repensar as mudanças metodológicas. Hoje, é bastante evidente que a sala de aula não é mais o palco onde se apresenta monólogo para um público passivo. 0 professor sabe que não basta falar para que os alunos aprendam. Isto significa que 0 trabalho em sala de aula, ou seja, o trabalho com ensino, exige um professor em permanente situação de investigação, o que implica condições de trabalho, formação adequada, criatividade, vontade, e compromisso político.

Ao longo das entrevistas, podemos dizer que os professores diante da situação que se encontra 0 ensino e devido à concorrência tecnológica que 
enfrentam no dia-a-dia em sala de aula, procuraram modificar o ensino através do estágio, como nos contou a professora Valentina: "(...) nós trabalhamos com imagem, fotografias (...) porque a imagem (...) é uma coisa que chega muito mais rápido do que o texto, do que qualquer coisa escrita (...)".

Já na mesma perspectiva de inovação no ensino a professora Lucimar nos narrou: (...) vídeo é uma coisa que eles gostam bastante (...) eles se ligam (...) acho que painel ajuda, tudo o que você puder assim visualizar".

Analisando as experiências vividas pelos professores entrevistados sobre o período do estágio, podemos dizer que é preciso que os professores universitários trabalhem mais no sentido de contribuir para que os estagiários percam esse medo que quase todos têm no momento de realizar o estágio principalmente quando eles estão sendo avaliados pelo professor orientador. Segundo os depoimentos este medo que quase todos os professores sentem atingem os estagiários que nunca atuaram em sala de aula e também os que já estão atuando há vários anos, como nos narrou a professora Lucimar:

A gente sempre vai pro estágio com o coração na mão né. Então, eu acho que a primeira coisa que deveria ser colocado o não sai trabalhar de talvez uma forma diferente com os alunos, trabalha um pouco esse medo que a gente tem, pra que te medo? (...) Eu acho que os professores poderiam ta mediando de forma um pouco diferente.

Embora atuando como professor desde o início do curso, no estágio ocorreu muito o medo e a insegurança, a princípio, devido a presença do professor orientador e, também, pela complexidade que o estágio representa, como nos contou o professor Lauci: “(...) Embora eu, quando fiz meu estágio eu me senti bastante inseguro, até pela presença do (...), mas se era coisa que eu acreditava não sofrer, mas acabei tendo essa insegurança de passar, de querer desfazer tudo (...)".

0 professor Anderson, apesar de já estar atuando como professor desde 1996, ele nos falou: "mesmo eu já sendo professor no estágio (...) deu um certo friozinho na barriga quando o professor orientador estava assistindo".

Já a professora Elenita nos apresentou uma sugestão em relação ao medo que ela também sentiu durante as aulas ministradas no período do 
estágio que este seja de: "mais horas aula, porque isso vai tirar o medo que a maioria tem de entrar numa sala de aula e com isso vai adquirindo experiência".

No sentido de diferir com as sugestões da professora Elenita que o medo vem da falta da experiência, trazemos a fala da professora Maria Regina, a qual afirmou que não teve dificuldades durante o período do estágio porque ela já estava atuando em sala de aula, nos relatou: "para mim não teve problemas (...) no estágio. Eu fiz tranquiilo o estágio, até porque eu já estava na sala de aula. E eu, tudo o que eu faço eu gosto muito sabe, eu gosto daquilo que eu faço".

Com relatos semelhantes aos da colega a professora Terezinha também nos afirmou que é muito importante para os estagiários já estarem atuando em sala de aula, porque isso vai fazer com que eles adquiram a experiência necessária para realizarem um bom trabalho no estágio, como ela nos contou:

0 estágio ele poderia ser assim oh, é quando faz estágio de observação já que é lá no $6^{\circ}$ período no caso de História que 0 aluno não viesse só observar, mas que ele tivesse a chance de estar começando a desenvolver parte de sua pesquisa (...) porque depois quando ele chega lá no $7^{\circ}$ período ele vai desenvolver a pesquisa já em sala de aula. Ele tenha a noção que pra ele vai ser muito mais interessante né. E ele também vai estar já com um pouquinho de experiência para estar desenvolvendo sua pesquisa, o seu trabalho em sala de aula.

Nas narrativas das professoras Maria Regina e Terezinha, evidenciamse que a experiência é a base para o bom desempenho do estagiário no ato do estágio. Enquanto que os professores Lauci e Anderson apesar de possuírem experiência em sala de aula esta não foi suficiente para manter a segurança e a tranquiilidade no momento do estágio.

Então, será que é falta de experiência? Ou de preparação por parte da Universidade aos futuros professores? Segundo PIMENTA (1995, p. 40):

Sugere-se que o curso de preparação deva ser equilibrado entre teoria e prática; que a prática antecipe muitas das dificuldades do jovem professor; que as aulas de práticas sejam complementadas com debates antes e depois, afim de ajudar os alunos a estabelecerem o senso de cooperação e interesse em desenvolverem a capacidade em vez de ansiedade. 
Outro aspecto contraditório no período do estágio é com relação ao planejamento das aulas, que não condiz com a "realidade" enfrentada no dia-a-dia do futuro professor, como nos contou o professor Lauci:

No estágio você tem que oferecer ao aluno todas as condições para a tua aula, no caso você vai ter que levar é tudo, tu vai ter que levar material (...) você tem que ter um planejamento, muitas vezes, você não tem na Escola, principalmente, se você trabalha sessenta horas, vocênão tem tempo de planejar. A Escolapúblicaestadual principalmente ela não oferece tempo de planejamento (...) na verdade qualquer um faz de conta que dá História, não dá História como um profissional habilitado (...) como deveria ser (...) qualquer um dá porque pega o livro didático, eu acho que tinha que ser abolido da escola. Porque o livro didático ele se torna refém née isso é a grande contradição do estágio. Porque no estágio pelo que eu vi no relato da minha turma ninguém praticamente utilizou o livro didático. Mas na hora de você trabalhar noventa por cento das Escolas hoje trabalha com o livro didático.

$\mathrm{Na}$ fala do professor percebe-se que na Universidade os acadêmicos são instruídos a construir os planos de aula e a produzirem os seus próprios textos para serem trabalhados em sala de aula com os alunos. Mas quando chegam na Escola para exercerem a profissão os planejamentos, os textos produzidos pelo então professor é substituído pelo livro didático.

Então, o porque a Universidade ensina um método de ensino que não condiz com a "realidade" que o futuro professor vai se deparar?

Segundo FREITAS (1992, p. 96): "a questão não é aumentar a prática em detrimento da teoria ou vice-versa, o problema consiste em adotarmos uma nova forma de produzir conhecimentos no interior dos cursos de formação do educador".

$\mathrm{Na}$ graduação realizada pelos depoentes, os acadêmicos são orientados no período do estágio a trabalhar com o tema do projeto de pesquisa. Esta experiência vem demonstrando grande participação dos alunos e assim proporcionando mais interesse pelas aulas de História. Pois, os temas das pesquisas que foram trabalhados fazem com que os alunos se sintam sujeitos da História e assim juntos possam produzir novos conhecimentos.

Segundo a professora Valentina, trabalhar o estágio vinculado ao TCC 
fez com que tivesse domínio do assunto e, assim, afastasse a insegurança no ato de realizar o estágio. Vejamos:

Mas eu achei interessante de ta trabalhando o estágio vinculado ao TCC. Porque com o TCC na pesquisa você se aprofunda bastante então, você está falando uma coisa que você tem o domínio do assunto, você sabe o que você está falando... Tu tem amplo conhecimento e isso eu acho muito interessante.

Outro aspecto destacado pelo professor Lauci é com relação às mudanças que vem ocorrendo na Educação Escolar, enquanto que na Universidade parece tudo estático. Por isso, o estágio é o momento para se inovar, mas este vai depender da concepção da Universidade como ele nos narrou:

A própria concepção de educação hoje no país está mudando com o governo Lula né. Há, Santa Catarina também tem avançado muito nesta questão de concepção de educação. Chapecó já avançou também, mas a Universidade está parada. Então é necessário que você inove no estágio, écom as mudanças que deve ocorrer no Curso e na própria Universidade (...) o estágio vai mudar a partir da concepção é de Universidade.

Nesta perspectiva de formação de professores, faz-se necessário que 0 processo nas mudanças do ensino ocorram primeiramente na universidade como nos diz KULCSAR (1991, p. 64): "é necessária uma revisão da prática do professor, do próprio saber gerado na universidade, que quase sempre retrata uma produção reinterpretada".

Com base na análise do depoimento dos professores entrevistados devemos pensar o estágio a partir de uma perspectiva nova, como espaço de trabalho e formação e também como encontro entre experiência e conhecimento, ou como nos diz, PONTUSCHKA (1991, p. 123):

Os estágios devem continuar com reformulações que os aproximem mais das necessidades dos licenciadose da realidade da escola pública, mas que haja contrapartida da universidade e dos órgãos educacionais competentes para tomar decisões. 
Em suma, o estágio é um centro de questionamentos por parte dos licenciandos e também pelos professores das escolas públicas, que nem sempre estão dispostos a ceder sua turma de alunos ao estagiário. Mas apesar de todos os obstáculos, cabe a nós continuarmos lutando para que sejam encontrados caminhos que levem a prática de ensino ou estágio supervisionado a superar as deficiências apresentadas, para dimensões mais produtivas.

Ao longo desse processo de diálogo entre a história oral e os diversos autores, citados, podemos afirmar que o estágio é considerado de extrema importância para a formação de professores. Porém, essa discussão também nos levou a perceber que o estágio necessita de várias modificações por parte da Universidade no sentido de estar revendo as metodologias no processo de formação de professores, a questão do medo na estréia, a insegurança, os problemas da dicotomia entre a teoria e a prática, o stress com o planejamento das aulas e o breve tempo de duração do estágio.

A busca por informações nos depoimentos nos proporcionou, inicialmente, descortinar as trajetórias dos professores depoentes até a conclusão da graduação, os quais nos levaram a refletir sobre as dificuldades financeiras, os motivos que os levaram optar pelo curso de História, e também pelo curso ser oferecido em Regime Especial.

Nesta análise percebemos que os Cursos de Licenciatura, neste caso o Curso de História são escolhidos geralmente pelos acadêmicos com baixo poder aquisitivo.

Num segundo momento, estes professores depoentes localizados nos municípios de Chapecó, Nonoai e Rio dos Índios apontaram seus diversos olhares sobre o curso de História identificando suas lacunas e demonstrando que apesar de ser considerado como um bom curso, uma graduação importante, ele está se tornando um curso deficitário, devido à falta de uma bibliográfica básica, pois os professores do curso seguem diferentes linhas de pensamento, resultando na falta de identidade no curso de História. A qual vem gerando divergências internas que acabam atingindo os acadêmicos, fazendo com que estes sofram injustiças no decorrer do curso, devido às opções pelos temas do Projeto de Pesquisa a ser desenvolvido no Curso.

Evidencia-se, assim, que ao concluir a graduação em História os acadêmicos levam em suas memórias, além das deficiências na formação, os 
ressentimentos, devido às injustiças sofridas no curso e logo em seguida a tristeza por serem esquecidos pela instituição e pelo próprio curso de História.

Esperamos que as memórias das experiências vividas pelos estagiários, que embora falem de um local específico possam ter relevância para outros estagiários deste e de outros curso de nosso país. Não queremos concluir deixando certezas absolutas e sim dúvidas, se não for realizado dessa forma como poderá ser o estágio?

\section{Referências}

BENJAMIN, Walter. Obras Escolhidas. Volume I. São Paulo: Brasiliense, 1993.

CONTRERAS, José. A Autonomia de Professores. São Paulo: Cortez, 1991.

CARVALHO, Silvana Maura Batista. Os Egressos da UEPG e o Ensino de História: A Formação de Professores. In: Anais III Encontro "Perspectivas do Ensino de História". Curitiba: UFPR, Aos Quatro Ventos, 1999.

FENELON, Déa Ribeiro. A Formação do Profissional de História e a Realidade do Ensino. In: CADERNOS CEDES, № 8. São Paulo: Cortez 1983.

FREITAS, Luis Carlos. Neotecnicismo e Formação do Educador. In: ALVES, Nilda (org.). Formação de Professores: pensar e fazer. São Paulo: Cortez, 1992.

FONSECA, Selva Guimarães. Ser Professor no Brasil: história oral de vida. Campinas, São Paulo: Papirus, 1997.

KENSKI, Vani Moreira. A Vivência Escolar dos Estagiários. E a Prática de Pesquisa em Estágios Supervisionados. In: FAZENDA, Ivani Catarina Arantes; PICONEZ, Stela C. Bertholo (Coords.). A Prática de Ensino e o Estágio Supervisionado. Campinas, São Paulo: Papirus, 1991.

KULCSAR, Rosa. 0 Estágio Supervisionado como Atividade Integradora. In: FAZENDA, Ivani Catarina Arantes; PICONEZ, Stela C. Bertholo (Coords.). A Prática de Ensino e O Estágio Supervisionado. Campinas, São Paulo: Papirus, 1991.

LEITE, Ana Cristina Teixeira; BRANDÃO, Márcia Nogueira. Estágio Supervisionado: uma modalidade de treinamento para aprimorar as competências profissionais. In: Coletâneas, II Encontro Nacional de Estágio. Minas Gerais: 1999.

PIMENTA, Selma Garrido. O Estágio na Formação dos Professores: Unidade Teoria e Prática ${ }^{\circ}$ Ed. São Paulo: Cortez, 1995. 
PONTUSCHKA, Nídia Nacib. A Formação Inicial do Professor de Geografia. In: FAZENDA, Ivani Catarina Arantes; PICONEZ, Stela C. Bertholo (Coords.). A Prática de Ensino e o Estágio Supervisionado. Campinas, São Paulo: Papirus, 1991.

PORTELLI, Alessandro. Tentando Aprender um Pouquinho. Algumas Reflexões sobre a ética na História Oral. In: Projeto História. № 15. São Paulo: EDUC, 1997, p. 13-33.

Forma e significado na História Oral. A pesquisa como um experimento em igualdade. In: Projeto História. N.14.São Paulo: EDUC, 1997, P.07-24.

REGO, Marion Villas Boas Sá. A Teoria na Prática é outra: Estágio Supervisionado nos Cursos de Formação de Professores. Rio de Janeiro: Ao Livro Técnico, 1992.

SCHMIDT, Maria Auxiliadora Moreira dos Santos. A Formação do Professor de História e o Cotidiano da Sala de Aula: entre o embate, o dilaceramento e o fazer histórico. In: Anais II Encontro Perspectivas do Ensino de História. São Paulo: FEUSP, 1996.

THOMPSON, Eduard Palmer. A miséria da Teoria. Rio de Janeiro: Zahar, 1981.

\section{Internship: Contributions to the history teachers formation}

\section{ABSTRACT}

This article has the search maimed "Internship: contributions to the history teachers formations" as a brose, and chose an objective undesired how the history teachers asses the internship while a constructive element of their initial formation. We used the oral history methodology. The state enters asses the Graduation, the internship importance, the internship existing blocks and even in the course. They criticized and suggested to contribute signifcativement to the internship activities improvement.

Key words: teachers formation, intenrship, experience, teorical and practical relations. 